\title{
Qualidade de grãos de arroz irrigado colhidos com diferentes graus de umidade em função da aplicação de fungicida
}

\author{
Grain quality of irrigated rice harvested at different moisture contents depending on fungicide \\ application \\ Gustavo Mack Teló ${ }^{*}$ Enio Marchesan ${ }^{\text {II }}$ Rafael Bruck Ferreira ${ }^{\text {II }}$ Alessandro Dal'Col Lúcio ${ }^{\text {II }}$ \\ Gerson Meneghetti Sarzi Sartori ${ }^{\mathrm{II}}$ Diogo Machado CezimbraI
}

\section{RESUMO}

O objetivo do trabalho foi verificar o efeito de fungicida aplicado na parte aérea das plantas, na quantidade de grãos inteiros de cultivares de arroz irrigado colhidos com diferentes graus de umidade. $O$ experimento foi conduzido durante o ano agrícola de 2007/08 e 2008/09, em delineamento experimental de blocos ao acaso em esquema fatorial, com cultivo em faixas $(4 \times 4 \times 6)$ e quatro repetições. $O$ fator principal, em faixas, foi composto por quatro cultivares de arroz irrigado: 'BR-IRGA 409', 'IRGA 417', 'IRGA 422CL' e 'IRGA 423'. Na subparcela, a aplicação de fungicida constituído da mistura formulada de propiconazol+trifloxistrobina foi realizada em diferentes estádios de desenvolvimento $\left(T_{1}\right.$ - sem aplicação de fungicida, $T_{2}$ - aplicação no estádio $R_{2}, T_{3}$ - aplicação no estádio $R_{3}$ e $T_{4}$ - aplicação no estádio $R_{2}+R_{4}$ ). A colheita do arroz foi realizada na sub-subparcela dentro de cada faixa e dentro de cada subparcela, com o grau de umidade média dos grãos de 24, 22, 20, 18, 16 e 14\%. Colheitas realizadas com grau de umidade média dos grãos inferior a $20 \%$ proporcionam redução no percentual de grãos inteiros para todos os tratamentos, entretanto com menor redução quando submetido a duas aplicações de fungicidas.

Palavras-chave: Oryza sativa L., atraso na colheita, grãos inteiros.

\section{ABSTRACT}

This study was carried out to verify the effect of fungicide application on rice grains of irrigated rice cultivars harvested with different moisture content. The experiment was conducted during the 2007/08 and 2008/09 season, and the experimental design was a strip plot with a factorial scheme $(4 \times 4 \times 6)$ and four replications. Main factor was composed by four irrigated rice cultivars: 'BR-IRGA 409', 'IRGA 417', 'IRGA

\begin{abstract}
422CL' $e$ 'IRGA 423'. In the sub-plot the fungicide was applied with the formulated mixture of propiconazole+trifloxystrobin in the plants canopy at different development stages $\left(T_{1}\right.$ untreated check, $T_{2}$ - application in $R_{2}$ stage, $T_{3}$ - application in $R_{3}$ stage and $T_{4}$ - application in $R_{2}+R_{4}$ stages). The different harvest times of the caryopsis were conducted in the sub-subplot in each strip and in each sub-plot, when they had 24, 22, 20, 18, 16 and 14 moisture content. Reduction of whole grains was observed in all treatments when grain moisture was under $20 \%$, however the reduction was smaller when the fungicide was applied twice.
\end{abstract}

Key words: Oryza sativa L., late harvesting, whole grains.

\section{INTRODUÇÃo}

A elevada produtividade e qualidade de grãos de arroz irrigado dependem de procedimentos de manejo aplicados no momento e na quantidade necessária. A época de semeadura é uma das práticas de maior impacto na obtenção de elevada produtividade, necessitando planejamento para realizar a semeadura no momento que proporcione maior rendimento potencial. De forma semelhante à semeadura, a colheita é uma etapa importante para obtenção de elevado percentual de grãos inteiros, característica que interfere na classificação do arroz e no valor pago no momento da comercialização.

O arroz colhido com grau elevado de umidade dos grãos requer secagem imediata para evitar

'Departamento de Fitotecnia, Centro de Ciências Rurais (CCR), Universidade Federal de Santa Maria (UFSM), 97105-900, Santa Maria, RS, Brasil. E-mail: gustavo.telo@yahoo.com.br. Autor para correspondência.

"Universidade Federal de Santa Maria (UFSM), Santa Maria, RS, Brasil. 
fermentação, afetando custos com mão-de-obra e energia na secagem (BINOTTI et al., 2007), além de RIBEIRO et al. (2004) relatarem ocorrência de defeitos, tais como grãos verdes, gessados e mal formados.

Por sua vez, a colheita de grãos realizada com baixo grau de umidade provoca aumento de degrane natural, acamamento de plantas e ataque de insetos, além da diminuição do percentual de grãos inteiros no beneficiamento, afetando também a germinação e o vigor das sementes (SMIDERLE et al., 2008). Segundo KUNZE \& PRASAD (1978), as fissuras não são causadas somente pela ação do calor, mas também pelo reumedecimento dos grãos, provocado pela variação brusca da umidade relativa do ar, por exemplo, por chuvas e garoas, dependendo do grau de umidade dos mesmos.

As cultivares de arroz respondem de forma diferenciada com relação à quebra de grãos durante o beneficiamento com o atraso da colheita, sendo que há indicativos de que a aplicação de fungicida pode contribuir para minimizar este efeito (RIBEIRO et al., 2004). No entanto, em função de ser uma tecnologia de uso recente, há necessidade de avaliar o efeito sobre a qualidade dos grãos, especialmente em colheitas realizadas com grau de umidade abaixo do preconizado, visto que a manifestação de doenças da parte aérea do arroz ocorre mais intensamente a partir da floração, em condição de clima tropical.

Nesse sentido, a hipótese é de que o uso de fungicida mantém a qualidade de grãos, especialmente quando colhidos com baixo grau de umidade, devido à redução da severidade de doenças, o que contribui para a manutenção da área foliar fotossinteticamente ativa por um período de tempo mais elevado.

Assim, o trabalho teve como objetivo verificar o efeito de fungicida aplicado na parte aérea das plantas, na quantidade de grãos inteiros de cultivares de arroz irrigado colhidos com diferentes graus de umidade.

\section{MATERIAL E MÉTODOS}

O experimento foi conduzido durante os anos agrícolas de 2007/08 e 2008/09, na área experimental de várzea do Departamento de Fitotecnia da Universidade Federal de Santa Maria (latitude: 2943’S, longitude: $53^{\circ} 48^{\prime} \mathrm{W}$ e altitude: $95 \mathrm{~m}$ ), em um Planossolo Háplico eutrófico arênico, pertencente à unidade de mapeamento Vacacaí (EMBRAPA, 2006).

O delineamento experimental utilizado foi de blocos ao acaso em esquema fatorial, com cultivo em faixas $(4 \times 4 \times 6)$ em quatro repetições. $O$ fator $A$, em faixas, foi composto por quatro cultivares de arroz irrigado:
'BR-IRGA409', 'IRGA417', 'IRGA422CL'e ‘IRGA423'. A semeadura ocorreu nos dias 17 de novembro de 2007 e 08 de dezembro de 2008, na densidade de $100 \mathrm{~kg} \mathrm{ha}^{-1}$ de semente para todas as cultivares, as quais foram previamente tratadas com o inseticida fipronil (62,5g i.a. ha ${ }^{-1}$ ) e com o fungicida thiram+carboxin (50g i.a. ha ${ }^{-1}$ + 50g i.a. ha-1). Cada parcela foi constituída por nove linhas de $7 \mathrm{~m}$ de comprimento, espaçadas em $0,17 \mathrm{~m}$, sendo colhida uma área útil de $0,95 \mathrm{~m}^{2}$ para cada grau de umidade. A adubação de base foi procedida com a distribuição na linha de semeadura de $17,5 \mathrm{~kg} \mathrm{ha}^{-1}$ de $\mathrm{N}$, $70 \mathrm{~kg} \mathrm{ha}^{-1}$ de $\mathrm{P}_{2} \mathrm{O}_{5}$ e $105 \mathrm{~kg} \mathrm{ha}^{-1}$ de $\mathrm{K}_{2} \mathrm{O}$, nos dois anos. Os demais tratos culturais foram conduzidos conforme as recomendações técnicas para a cultura (SOSBAI, 2007).

O fator C foi constituído pela aplicação de fungicida na subparcela dentro de cada faixa, na parte aérea das plantas, em diferentes estádios de desenvolvimento da cultura $\left(\mathrm{T}_{1}\right.$ - sem aplicação de fungicida; $\mathrm{T}_{2}$ - aplicação no estádio $\mathrm{R}_{2} ; \mathrm{T}_{3}$ - aplicação no estádio $\mathrm{R}_{3}$, e $\mathrm{T}_{4}$ - aplicação nos estádios $\mathrm{R}_{2}+\mathrm{R}_{4}$, segundo a escala proposta por COUNCE et al. (2000)). As aplicações de fungicida na parte aérea das plantas foram realizadas pela pulverização da mistura formulada de propiconazol+trifloxistrobina, na dose de 93,75g i.a. ha $^{-1}+93,75$ g i.a. ha-1, respectivamente, para os tratamentos com uma aplicação de fungicida (tratamentos $\mathrm{T}_{2}$ e $\mathrm{T}_{3}$ ), e na dosagem de 75,0g i.a. ha-1 + $75,0 \mathrm{~g}$ i.a. ha ${ }^{-1}$ da mistura formulada de propiconazol+trifloxistrobina, quando realizadas duas aplicações de fungicida (tratamento $\mathrm{T}_{4}$ ). As aplicações foram realizadas com pulverizador costal propelido a $\mathrm{CO}_{2}$ (pressão de $40 \mathrm{lbs} \mathrm{pol}^{-2}$ ), utilizando-se barra com quatro pontas de pulverização cone vazio (Jacto JA2), espaçadas $0,50 \mathrm{~m}$, com volume de calda ajustado para 229L ha ${ }^{-1}$ para o primeiro ano e 232L ha-1 para o segundo ano.

$\mathrm{O}$ fator $\mathrm{D}$ foi constituído da sub-subparcela dentro de cada faixa e dentro de cada subparcela, pela colheita do arroz com diferentes graus de umidade médio das cariopses $(24,22,20,18,16$ e $14 \%$ de umidade). O monitoramento do grau de umidade médio do arroz foi realizado sempre no mesmo horário, no final da manhã, durante o seu período de colheita, a qual, juntamente com a trilha, foi realizada manualmente, seguida por pré-limpeza e secagem forçada com monitoramento da temperatura de $37^{ \pm} 2^{\circ} \mathrm{C}$ até atingir umidade de $13 \%$. Posteriormente, o material experimental foi armazenado em local seco por três meses para início das avaliações.

O percentual de grãos inteiros foi obtido das amostras que foram armazenadas previamente, constituindo-se de quatro subamostras de $100 \mathrm{~g}$ para cada tratamento e realizado o beneficiamento em 
testadora de arroz. Para a aferição da máquina, utilizouse uma amostra padrão de arroz, obtida no órgão oficial de classificação de grãos no Estado do Rio Grande do Sul (ASCAR/EMATER). A aferição da máquina resultou no tempo de 10 segundos para o descascamento e de 60 segundos para o brunimento da amostra. A separação dos grãos inteiros e quebrados foi realizada com o trieur, que acompanha a testadora. A cada 16 amostras, efetuou-se a verificação da testadora com a amostra padrão. O percentual de grãos inteiros após o polimento foi obtido de forma direta, pela pesagem dos grãos inteiros e quebrados.

Os resultados obtidos foram submetidos ao teste das pressuposições do modelo matemático (normalidade e homogeneidade das variâncias) e transformados para $y t=\sqrt{(y+0,5)}$. Os dados apresentados são valores não transformados. A análise da variância dos dados do experimento foi realizada através do teste $\mathrm{F}$ e as médias dos fatores quantitativos, quando significativas, submetidas à análise de regressão polinomial, testandose os modelos linear e quadrático. Para os resultados expressos graficamente, determinou-se o intervalo de confiança $(\mathrm{P} \leq 0,05)$.

\section{RESULTADOS E DISCUSSÃO}

\section{Safra 2007/08}

Entre as variáveis em estudo (cultivar $\mathrm{x}$ aplicação de fungicida $\mathrm{x}$ umidade de colheita), houve interação tripla, atendendo um comportamento quadrático polinomial (Figura 1). O maior percentual de grãos inteiros foi obtido quando a colheita foi realizada com grau de umidade médio entre 22 e 20\%, sendo observada pequena redução no percentual com umidade média de $24 \%$, para as cultivares 'BR-IRGA 409' e 'IRGA 417'. Com o atraso na colheita, houve redução no percentual de grãos inteiros para todas as cultivares, porém com respostas distintas entre elas. A cultivar 'IRGA 422CL' evidenciou a maior redução do percentual de grãos inteiros, diferenciando-se das demais quando realizada colheita com grau de umidade médio inferior a $20 \%$.

Pelos resultados obtidos, os maiores valores do percentual de grãos inteiros apontam para colheitas realizadas com grau de umidade médio de 22 a 20\%, estando de acordo com resultados de RIBEIRO et al. (2004), que avaliaram os efeitos do atraso da
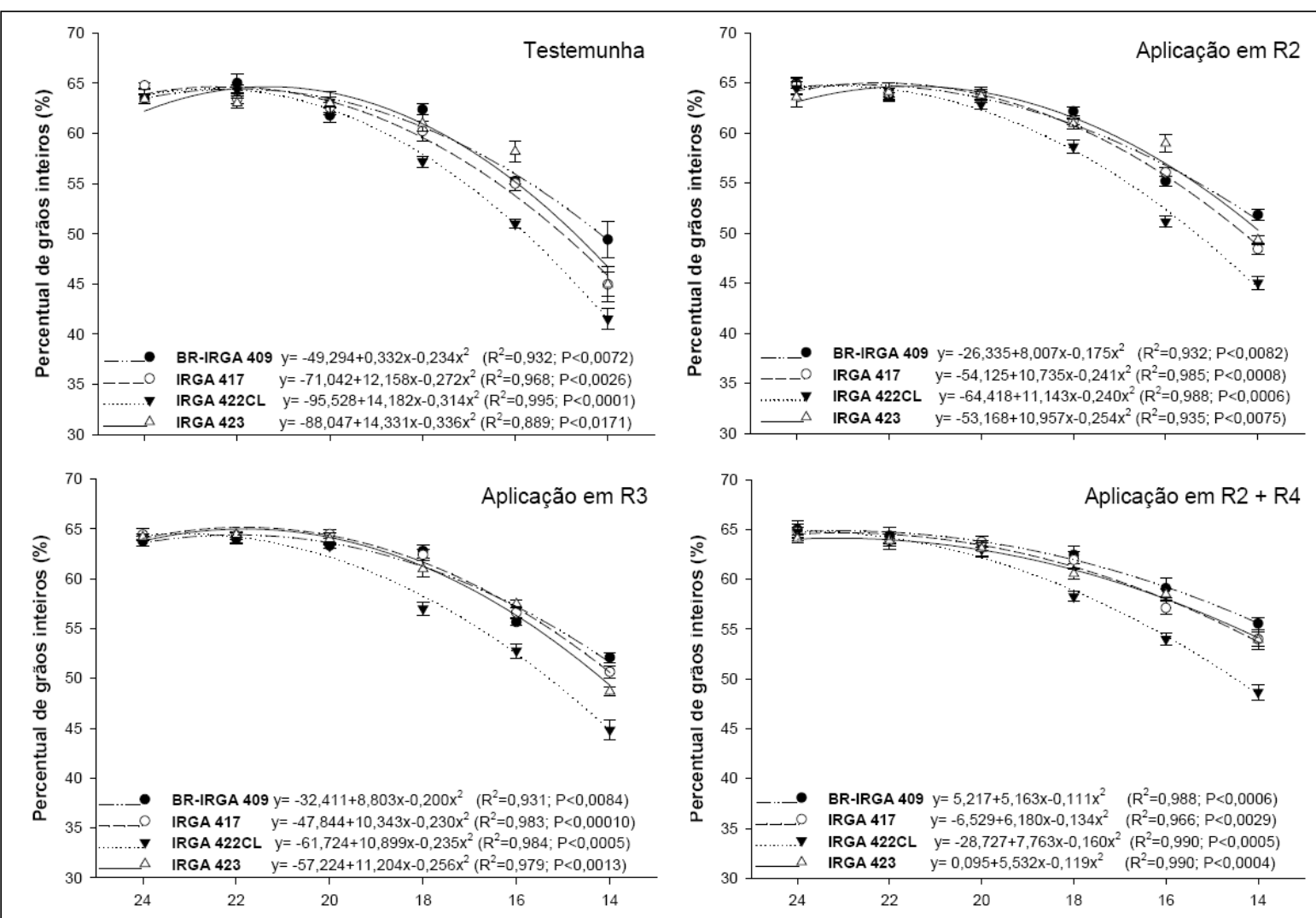

Figura 1 - Percentual de grãos inteiros de quatro cultivares de arroz irrigado, em resposta ao momento de aplicação de fungicida com mistura formulada de propiconazol+trifloxistrobina, colhidos com diferentes graus de umidade na safra $2007 / 08$. Santa Maria-RS, 2011. 
colheita de 12 cultivares de arroz. A obtenção dos maiores percentuais com essas umidades médias dos grãos está relacionada, segundo KUNZE (1986), ao comportamento higroscópico destes, os quais absorvem e perdem água até atingirem o equilíbrio com a umidade relativa do ar do ambiente. A umidade relativa do ar e a temperatura são os principais elementos meteorológicos que influenciam na formação de fissuras nos grãos de arroz (KUNZE et al., 1988). Essa situação é mais evidenciada na ocorrência de temperaturas elevadas durante o período da noite, como destacou MOHAMMED \& TARPLEY (2010), em função do aumento da taxa de respiração das cariopses, proporcionando a formação de fissuras nos grãos. Com a redução da umidade dos grãos, as trocas de umidade entre estes e o ambiente proporcionam a formação de fissuras, o que ocorre em menor intensidade quando eles ainda estão com umidade mais elevada.

A aplicação de fungicida não influenciou no percentual de grãos inteiros para colheitas realizadas com grau de umidade médio entre 24 a $20 \%$. No entanto, o uso de duas aplicações de fungicida proporcionou os maiores percentuais de grãos inteiros para colheitas realizadas com grau de umidade entre 16 e $14 \%$.

Para a cultivar 'IRGA 422CL', com uma redução mais acentuada do percentual de grãos inteiros com o decréscimo da umidade de colheita, o uso de duas aplicações de fungicida proporcionou menor redução da quantidade de grãos inteiros, quando comparada à testemunha, em colheita realizada com grau de umidade médio dos grãos com 16 e 14\%. Além disso, o uso de duas aplicações de fungicida manteve elevado o percentual de grãos inteiros, quando colhidos com até $18 \%$ de umidade, o que não foi observado quando realizada apenas uma aplicação de fungicida. Isso pode estar correlacionado diretamente com a manutenção da área foliar e redução da senescência das folhas das plantas (SOFIATTI et al., 2006), proporcionada principalmente pelo uso de duas aplicações de fungicida.

\section{Safra 2008/09}

Para o percentual de grãos inteiros (Figura 2), o comportamento foi semelhante ao observado no ano anterior, com interação tripla entre os fatores (cultivares $\mathrm{x}$ aplicação de fungicida $\mathrm{x}$ umidade de colheita), ajustando-se a um comportamento quadrático polinomial. O percentual mais elevado ocorreu quando os grãos foram colhidos com grau de umidade médio entre 22 a $20 \%$, confirmando os resultados obtidos na safra 2007/08. Autores como GROTH(2005) e SOFIATTI et al. (2006) não observaram influência da aplicação de fungicida na parte aérea das plantas de arroz sobre o percentual de grãos inteiros quando colhidos com grau de umidade preconizado pela pesquisa, associando os valores do percentual à característica genética das cultivares.

A redução no percentual de grãos inteiros foi observada com o decréscimo do grau de umidade médio destes para todas as cultivares, mas, com comportamento distinto entre elas, especialmente quando realizada a colheita com grau de umidade médio inferior a 20\%. Destaca-se a cultivar 'IRGA 422CL', com a maior redução do percentual de grãos inteiros para colheitas realizadas com o grau de umidade inferior a $20 \%$, confirmando resultados obtidos na safra anterior. Para essa cultivar, o planejamento da atividade de produção envolve colheitas com umidade média dos grãos entre 24 a $20 \%$.

Resultados semelhantes foram encontrados por MARCHEZAN et al. (1993), quando observaram que colheitas realizadas com o grau de umidade de 23 a $18 \%$ proporcionaram maior percentual de grãos inteiros em arroz irrigado. Visando determinar qual a amplitude de variação da umidade relativa do ar seria suficiente para causar fissuras nos grãos, KUNZE et al. (1988) verificaram que a variação de $40 \%$ ou mais causou fissuras apenas quando o grau de umidade do grão foi inferior a 18\%, evidenciando que o efeito das condições meteorológicas no rendimento do grão depende de seu conteúdo de água. A associação entre a diferença de umidade relativa do ar máxima e mínima e o período em que a umidade relativa do ar permanece maior do que 90\% promovem fissuras nos grãos, quando estes estão com grau de umidade abaixo de um valor crítico de $18 \%$ (MARCHEZAN, 1995). Essa situação pode ser relacionada ao observar os percentuais de grãos inteiros obtidos nas colheitas realizadas com grau de umidade médio inferior a $20 \%$, em função de permanecerem mais tempo no campo, sujeitos assim a interferências das condições meteorológicas.

Ao estudar o percentual de grãos inteiros para cultivares de arroz de sequeiro, em razão do atraso da colheita, FONSECA et al. (2004) destacaram que a principal causa de quebra está relacionada à absorção de água, mais especificamente, quando a umidade dos grãos está em torno de $16 \%$, pois, ocorrendo chuva, os grãos reidratam bruscamente, o que causa o trincamento e posterior quebra no beneficiamento. Segundo esses autores, as cultivares diferenciam-se muito quanto à capacidade de suportar essa reumidificação, podendo haver diferença quanto ao ponto ideal de colheita entre as cultivares.

O uso de fungicida não diferiu da testemunha (sem aplicação de fungicida) para as colheitas realizas com grau de umidade médio entre 24 

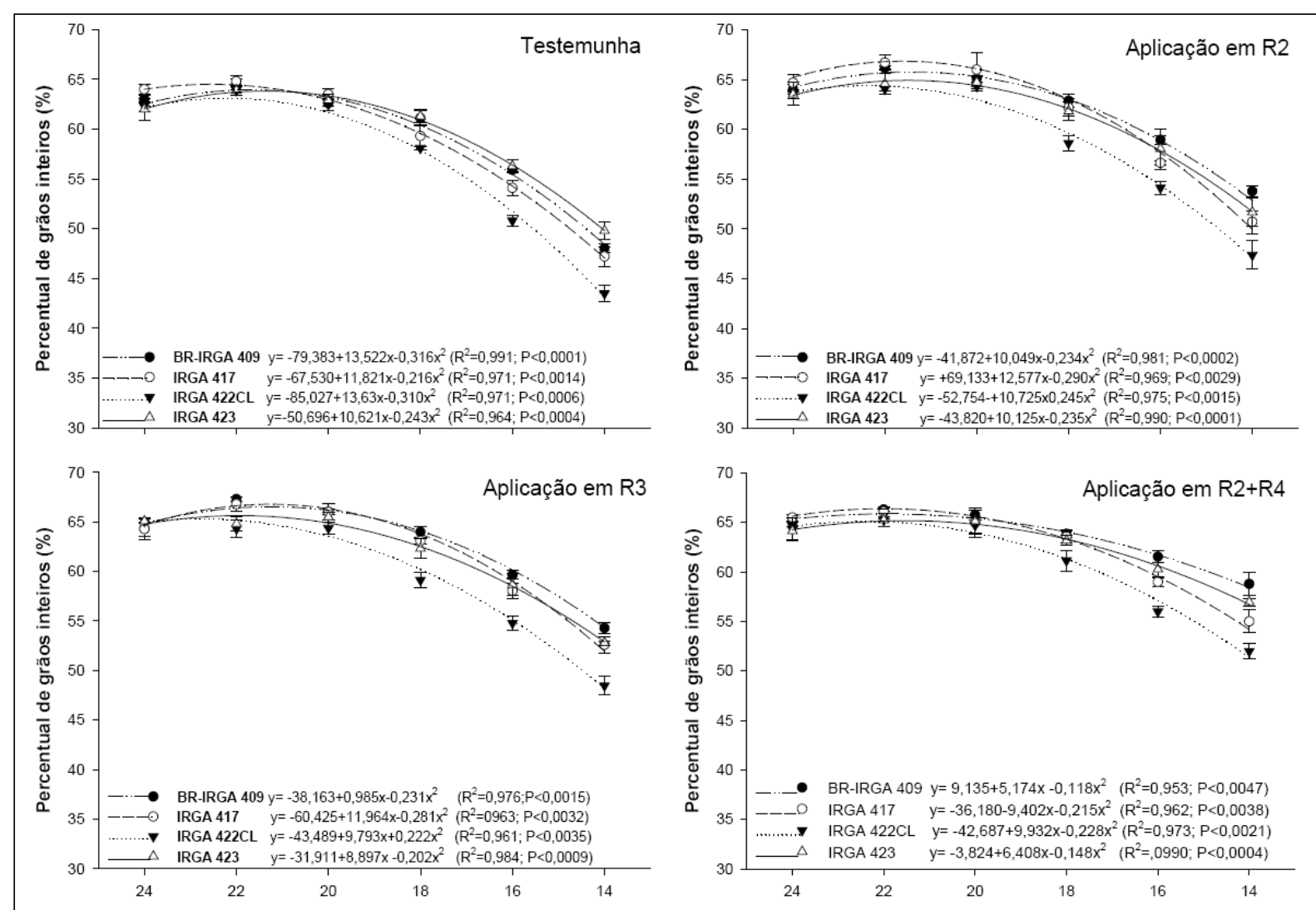

Figura 2 - Percentual de grãos inteiros de quatro cultivares de arroz irrigado, em resposta ao momento de aplicação de fungicida com mistura formulada de propiconazol+trifloxistrobina, colhidos com diferentes graus de umidade na safra 2008/09. Santa Maria-RS, 2011.

a $20 \%$, com elevado percentual de grãos inteiros. No entanto, a realização de uma ou duas aplicações de fungicida proporcionou maior percentual de grãos inteiros, quando comparado à testemunha para as colheitas realizadas com o grau de umidade inferior a 20\%. Duas aplicações (no estádio $\mathrm{R}_{2}+\mathrm{R}_{4}$ ) resultaram num acréscimo, em média, de $16,4 \%$ no percentual de grãos inteiros, quando comparados com a testemunha, para colheita realizada com 14\% de umidade dos grãos, em função da severidade de doenças foliares. Além disso, duas aplicações de fungicidas em colheitas, realizadas com grãos colhidos com umidade abaixo de 18\%, auxiliaram na manutenção do percentual de grãos inteiros, quando comparado com o uso de uma aplicação de fungicida.

De modo geral, nas duas safras agrícolas (2007/08 e 2008/09), a aplicação de fungicida não influenciou no percentual de grãos inteiros para colheitas realizadas com grau de umidade médio entre 24 a $20 \%$ (Figura 3).

Com relação às colheitas realizadas com grau de umidade médio entre 18 e 16\%, o uso de uma ou duas aplicações de fungicida refletiu positivamente no percentual de grãos inteiros comparado à testemunha, não havendo diferença quanto ao momento da aplicação do fungicida. Para a colheita dos grãos, realizada com grau de umidade média de $14 \%$, o uso de duas aplicações de fungicidas proporcionou maior percentual de grãos inteiros em relação à uma aplicação, independente do estádio de desenvolvimento das plantas e, em comparação à testemunha (sem aplicação), houve um acréscimo de 15\% do percentual em função de duas aplicações de fungicida. O uso de fungicida se faz importante em condições adversas à cultura, como elevada severidade de doenças foliares que resultam em senescência precoce e reduzem a atividade fotossintética da planta, podendo interferir no percentual de grãos inteiros (GROTH \& BOND, 2007).

Os resultados permitem enfatizar que o atraso da colheita do arroz irrigado causa impactos negativos no percentual de grãos inteiros, sendo importante planejar as operações para realizar a colheita do arroz com grau de umidade que permita elevado percentual de grãos inteiros.

Ciência Rural, v.41, n.6, jun, 2011. 


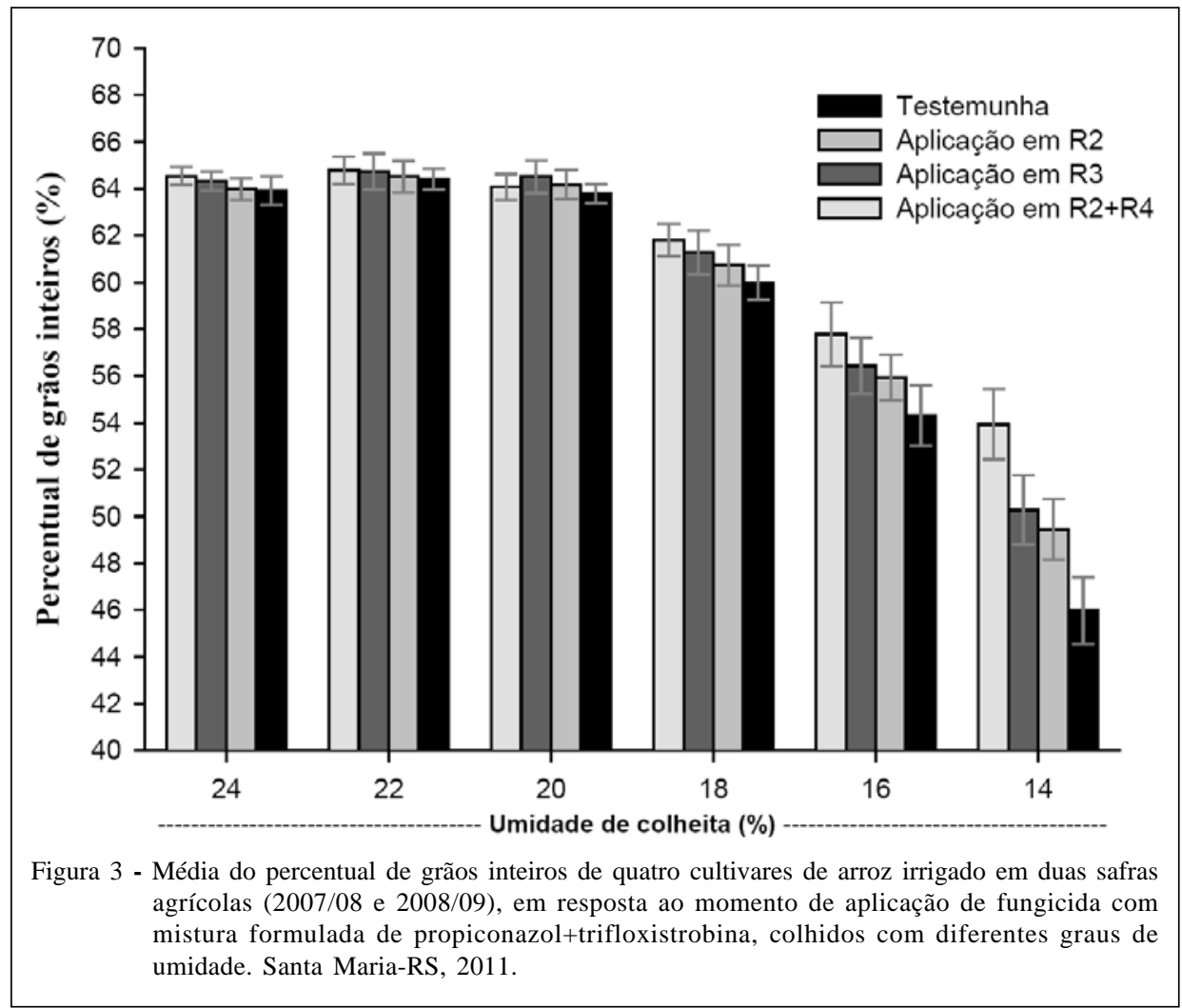

\section{CONCLUSÃO}

O uso de fungicida não influencia no percentual de grãos inteiros do arroz quando a colheita é realizada com grau de umidade médio dos grãos entre 24 a $20 \%$. O percentual de grãos inteiros é reduzido quando o arroz é colhido com grau de umidade médio dos grãos inferior a $20 \%$, independentemente do uso de fungicida. As cultivares de arroz respondem de forma diferenciada em relação ao percentual de grãos inteiros, sendo que para a 'IRGA 422CL' há maior redução quando a colheita é realizada com umidade abaixo de $20 \%$.

\section{AGRADECIMENTOS}

À Coordenação de Aperfeiçoamento de Pessoal de Nível Superior (CAPES) e ao Conselho Nacional de Desenvolvimento Científico e Tecnológico (CNPq), pelo suporte financeiro e pelas bolsas de estudo e produtividade aos pesquisadores Teló, Marchesan, Ferreira e Lúcio. Aos integrantes do Grupo de Pesquisa em Arroz e Uso Alternativo de Várzea da UFSM.

\section{REFERÊNCIAS}

BINOTTI, F.F.S. et al. Momento de colheita e períodos de armazenamento no rendimento industrial e na qualidade fisiológica do arroz de terras altas. Acta Scientiarum Agronomy, Maringá, v.29, n.2, p.219-226, 2007. Disponível em: <http://periodicos.uem.br/ojs/index.php/ActaSciAgron/ article/viewArticle/255>. Acesso em: 05 mar. 2011. doi: 10.4025/actasciagron.v29i2.255.

COUNCE, P.A. et al. A uniform, objective and adaptive system for expressing rice development. Crop Science, Madison, v.40, n.2, p.436-443, 2000. Disponível em: <http:// cses.uark.edu/1815.htm>. Acesso em: 28 nov. 2010.

EMBRAPA. Centro Nacional de Pesquisa de Solos. Sistema brasileiro de classificação de solos. Brasília: Embrapa Rio de Janeiro, 2006. 306p.

FONSECA, J.R. et al. Ponto de colheita dos cultivares de arroz de terras altas BRS Liderança, BRS Talento e BRSMG Curinga. Revista Ceres, Viçosa, v.296, n.51, p.535-540, 2004.

GROTH, D.E. Azoxystrobin rate and timing effects on rice sheath blight incidence and severity and rice grain and milling yields. Plant Disease, Saint Paul, v.89, n.11, p.1171-1174, 2005. Disponível em: <apsjournals.apsnet.org/doi/pdf/10.1094/ PD-89-1171>. Acesso em: 14 mar. 2011. doi: 10.1094/PD89-1171.

GROTH, D.E.; BOND, J.A. Effects of cultivars and fungicides on rice sheath blight, yield, and quality. Plant Disease, Saint Paul, v.91, n.12, p.1647-1650, 2007. Disponível em: <apsjournals.apsnet.org/doi/pdf/10.1094/PDIS-91-12-1647>. Acesso em: 14 mar. 2011. doi:10.1094/PDIS-91-12-1647. 
KUNZE, O.R.; PRASAD, D. Grain fissure in potentials in harvesting and drying of rice. Transactions of ASAE, Miami, n.21, p.361-366, 1978.

KUNZE, O.R. Influencia de la absorción de humedad en la calidade de molturación del arroz cascara. Noticiário de la Comissión Internacional del Arroz, Rome, v.35, n.2, p.13, 1986 .

KUNZE, O.R. et al. Fissured rice related to grain moisture weather and fertilization rates. In: INTERNATIONAL WINTER MEETING OF THE AMERICAN SOCIETY OF AGRICULTURAL ENGINEERS, 1988, St. Joseph. Proceedings... St. Joseph: American Society of Engineers, 1988. 14p.

MARCHEZAN, E. et al. Relações entre época de colheita e rendimento de grãos inteiros de cultivares de arroz irrigado. Pesquisa Agropecuária Brasileira, Brasília, v.28, n.7, p.843848, 1993.

MARCHEZAN, E. Efeito de elementos meteorológicos na época de colheita sobre a quantidade de grãos inteiros em arroz. Ciência Rural, Santa Maria, v.25, n.2, p.191-195, 1995. Disponível em: <http://www.scielo.br/scielo.php?pid=S0103$84781995000200001 \&$ script $=$ sci_abstract $\&$ tlng $=p t>$. Acesso em: 14 mar. 2011. doi: 10.1590/S0103-84781995000200001.

MOHAMMED, A.R.; TARPLEY, L. Effects of night temperature, spikelet position and salicylic acid on yield and yield-related parameters of rice (Oryza sativa L.) plants.
European Journal of Agronomy, Amsterdam, v.33, n.2, p.117123, 2010. Disponível em: <http://onlinelibrary.wiley.com/doi/ 10.1111/j.1439-037X.2010.00439.x/pdf>. Acesso em: 14 mar. 2011. doi:10.1111/j.1439-037X.2010.00439.x.

RIBEIRO, G.J. et al. Efeitos do atraso na colheita e do período de armazenamento sobre o rendimento de grãos inteiros de arroz de terras altas. Ciência e Agrotecnologia, Lavras, v.28, n.5, p.1021-1030, 2004. Disponível em: <http:// w w w. s c i e lo.br/s c i e lo.p h p ? p id = S 1413 $70542004000500008 \&$ script $=$ sci_abstract $\&$ tlng $=p t>$. Acesso em: 14 mar. 2011. doi: 10.1590/S1413-70542004000500008.

SOFIATTI, V. et al. Efeitos de regulador de crescimento, controle de doenças e densidade de semeadura na qualidade industrial de grãos de arroz. Ciência Rural, Santa Maria, v.36, n.2, p.418-423, 2006. Disponível em: <http:// w w w. s c i e l o.br/s c i e lo.ph p ? p i d = S 0103 $84782006000200010 \&$ script $=$ sci_abstract $\&$ tlng $=\mathrm{pt}>$. Acesso em: 14 mar. 2011. doi: 10.1590/S0103-84782006000200010.

SMIDERLE, O.J. et al. Épocas de colheita e qualidade fisiológica das sementes de arroz irrigado cultivar BRS 7 Taim, em Roraima. Revista Brasileira de Sementes, Brasília, v.30, n.1, p.74-80, 2008. Disponível em: <http://www.scielo.br/scielo.php?pid=S010131222008000100010\&script=sci_abstract\&tlng=pt $>$. Acesso em: 18 mar. 2011. doi: 10.1590/S0101-31222008000100010.

SOCIEDADE SUL-BRASILEIRA DE ARROZ IRRIGADO (SOSBAI). Arroz irrigado: Recomendações técnicas da pesquisa para o Sul do Brasil. Pelotas-RS: SOSBAI, 2007. 161p. 